\title{
IMPLEMENTASI METODE SIMPLE ADDITIVE WEIGHTING (SAW) PADA PENILAIAN KINERJA STANDAR PELAYANAN MINIMAL SARANA DAN PRASARANA PENDIDIKAN DASAR PADA KOTA SAMARINDA
}

\author{
Haidi Nurhadinata ${ }^{1}$, Irwansyah ${ }^{2}$, Abdul Najib ${ }^{3}$ \\ ${ }^{1,2,3)}$ Politeknik Negeri Samarinda, Prodi Teknik Informatika \\ E-mail: haidinurhadinata@gmail.com, irwansyah_ugm@yahoo.co.id, abdulnajib@polnes.ac.id.
}

\begin{abstract}
Abstrak - Kualitas suatu sekolah bergantung pada pelayanan yang ada. Demi meningkatkan kinerja sekolah, standar pelayanan minimal sebagai acuan penilaian pada pendidikan dasar. Selama ini proses penilaian kinerja pada pendidikan dasar oleh Dinas Pendidikan, dilakukan secara manual karena belum terdapat sistem penilaian dengan memanfaatkan teknologi informasi, sehingga memerlukan waktu yang lama dan kurang akurat. Hal inilah yang menjadi dasar penelitian yang akan dilakukan. Selanjutnya penelitian yang dilakukan adalah membuat sebuah sistem pendukung keputusan yang dapat digunakan oleh Dinas Pendidikan Kota Samarinda dalam memutuskan sekolah terbaik berdasarkan kinerja. Aplikasi ini mampu mengatasi permasalahan yang ada pada proses penilaian kinerja pada sekolah - sekolah. Metode yang digunakan pada sistem pendukung keputusan ini adalah Simple Additive Weighting (SAW). Metode SAW dapat di implementasikan dengan baik dalam pemilihan sekolah terbaik. Akurasi yang diperoleh dari sistem ini adalah $100 \%$.
\end{abstract}

Kata Kunci - standar pelayanan minimal, pendidikan dasar, pendidikan dasar, Simple Additive Weighting $(\mathrm{SAW})$.

\section{PENDAHULUAN}

\subsection{Latar Belakang}

Standar pelayanan minimal pendidikan adalah acuan dalam perencanaan program dan penganggaran pencapaian target masing - masing daerah kabupaten/kota[1].

Simple Additive Weighting adalah mencari penjumlahan terbobot dari rating kinerja pada setiap alternatif pada semua atribut[4][5].

Berdasarkan uraian di atas, pada penilitian ini membahas tentang bagaimana menerapkan perhitungan metode SAW pada penilaian kinerja standar pelayanan minimal pada pendidikan dasar Kota Samarinda.

\section{DASAR TEORI}

\subsection{METODOLOGI DAN BAHAN} PENELITIAN

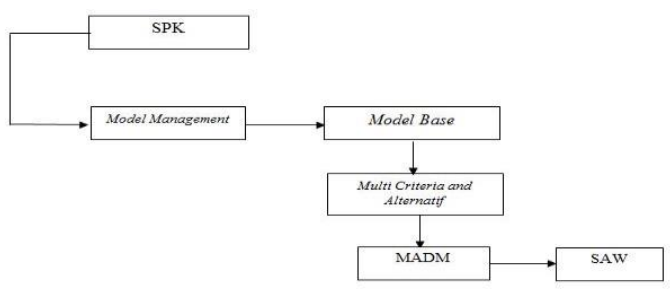

Gambar. 1. Diagram Alir Kerangka Konsep
Sistem pendukung keputusan adalah sistem penghasil informasi pada suatu masalah tertentu yang harus di pecahkan oleh pembuat keputusan[4].

Di dalam sistem pendukung keputusan (SPK) beberapa komponen yang penting salah satunya Model Management Subsystem[4].

Model Management Subsystem melibatkan model finansial, statistikal, management science, atau berbagai model kuantitatif lainnya, sehingga dapat memberikan kemampuan analitis, dan manajemen software yang diperlukan[4]. Selanjutnya beberapa fasilitas pengolahan model salah satunya Model base.

Model base adalah suatu model yang berebntuk hasil ide kedalam format penilaian yang berdasarkan kualitas sebagai pengambil keputusan[4]. Selanjutnya Model base memiliki beberapa bagian lagi salah satunya Multi criteria and alternatif.

Multi criteria and alternatif merupakan model SPK yang memiliki banyak kriteria dan alternatif[4]. Dalam kasus multi attribute decision making(MADM) memiliki metode untuk menyelesaikan kasusnya, salah satunya yaitu SAW. 


\subsubsection{Kriteria}

Indikator kriteria ditandai dengan $\mathrm{C} 1$ sampai C5. Kriteria yang dijadikan sebagai acuan pengambilan keputusan adalah sebagai berikut.

$\mathrm{C} 1$ = Rombongan belajar tidak melebihi 36 murid dan

tersedia 1 ruang kelas. yang

C2 = Setiap sekolah terdapat ruang lab IPA cukup 36 peserta.

$\mathrm{C} 3$ = Setiap sekolah terdapat 1 ruang guru yang dilengkapi meja dan kursi.

C4 = Setiap sekolah tersedia buku.

C5 = Setiap sekolah memiliki buku pengayaan dan buku referensi.

\subsubsection{Alternatif}

Pada tahap ini penulis akan menentukan daftar sekolah (alternatif) yang akan digunakan pada perhitungan.Di sini penulis menggunakan sampel sekolah tingkat sekolah menengah pertama (SMP) berada di wilayah kecamatan Samarinda Ulu, yang ditandai dengan A1 sampai dengan A14 pada tabel 1.

TABEL 1. DATA SEKOLAH

\begin{tabular}{|c|c|}
\hline Kode & Nama Sekolah \\
\hline A1 & SMP Negeri 1 \\
\hline A2 & SMP Negeri 4 \\
\hline A3 & SMP Negeri 5 \\
\hline A4 & SMP Negeri 7 \\
\hline A5 & SMP Negeri 22 \\
\hline A6 & SMP Negeri 24 \\
\hline A7 & SMP Negeri 39 \\
\hline A8 & SMP Katolik 1 WR. Soepratman \\
\hline A9 & SMP Muhammadiyah 3 \\
\hline A10 & SMP Immanuel \\
\hline A11 & SMP IT Cordova \\
\hline A12 & SMP IT Al Firdaus \\
\hline A13 & SMP Ma'arif \\
\hline A14 & SMP Tunas Kelapa \\
\hline
\end{tabular}

\subsection{Proses $S A W$}

Secara garis besar metode proses perhitungan SAW ditunjukan pada gambar berikut.

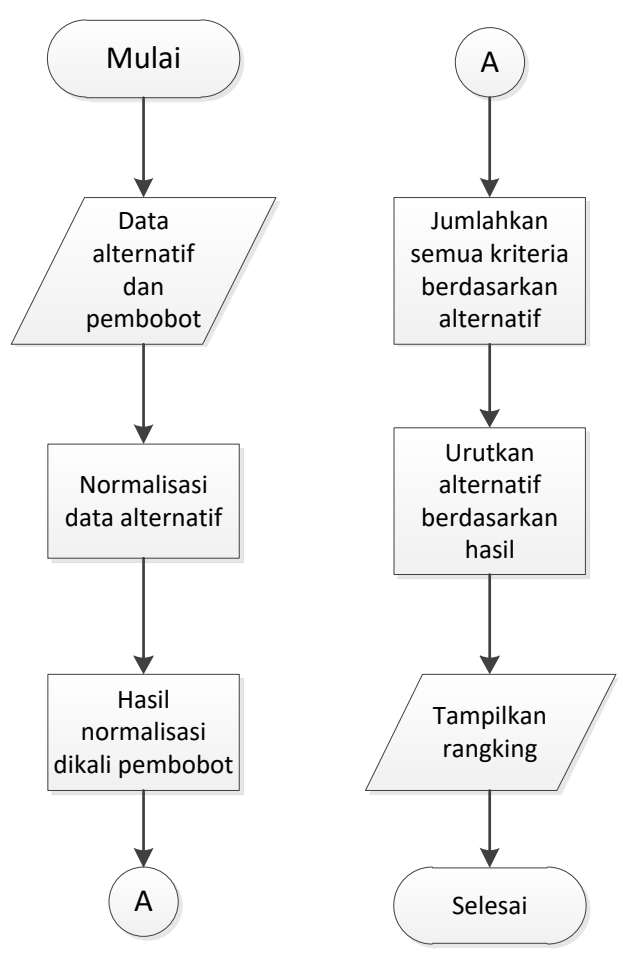

Gambar. 2. Flowchat perhitungan dengan metode SAW

Berdasarkan pada Gambar 2 proses awal setelah menginput data alternatif dan pembobot, yaitu proses normalisasi data alternatif. Normalisasi menggunakan persamaan (1).

$$
r_{i j}=\frac{\operatorname{Min}_{i}\left\{\mathrm{x}_{i j}\right\}}{X i j}
$$

Dimana :

$r_{i j}=$ data yang sudah dinormalisasi.

$$
x_{i j}=\text { data. }
$$

$\operatorname{Min}_{i}\left\{x_{i j}\right\}=$ data yang memiliki nilai minimal pada tiap kriteria.

Selanjutnya proses perhitungan hasil normalisasi dikali pembobot menggunakan persamaan (2).

$$
V_{i}=w_{j} r_{i j}
$$


Nurhadinata, dkk., Implementasi Metode Simple Additive Weighting (SAW) Pada Penilaian Kinerja Standar Pelayanan Minimal Sarana dan Prasarana Pendidikan Dasar Pada Kota Samarinda

Dimana :

$V_{i}=$ data hasil perkalian rating kinerja yang ternormalisasi dengan nilai pembobot.

$w_{j}=$ nilai pembobot preferensi.

$r_{i j} \quad=$ rating kinerja yang ternormalisasi

Selanjutnya proses penjumlahan semua kriteria berdasarkan alternatif menggunakan persamaan (3).

$$
U_{i}=\sum_{j=1}^{n} V_{i}
$$

$U_{i}=$ data hasil penjumlahan semua kriteria berdasarkan alternaif.

$\sum_{j=1}^{n}=$ penjumlah semua kriteria berdasarkan alternatif.

Selanjutnya alterantif di irutkan berdasarkan hasil dari yang tertinggi sampai terendah. Menampilkan hasil ranking dari hasil perhitungan.

\section{HASIL DAN PEMBAHASAN}

\subsection{Data Penelitian}

Dalam proses SAW menggunakan nilai matriks keputusan sebagai bahan perhitungan . oleh karena itu nilai pada setiap alternatif di setiap kriteria nilai terbesar adalah terbaik. Pengambil keputusan memberikan nilai pembobot setiap kriteria sebagai berikut.

$$
\begin{aligned}
& \mathrm{C} 1=0,2 \\
& \mathrm{C} 2=0,2 \\
& \mathrm{C} 3=0,2 \\
& \mathrm{C} 4=0,2 \\
& \mathrm{C} 5=0,2
\end{aligned}
$$

\begin{tabular}{|c|c|c|c|c|c|}
\hline \multirow{2}{*}{ Alternatif } & \multicolumn{5}{|c|}{ Kriteria } \\
\hline & $\mathrm{C} 1$ & $\mathrm{C} 2$ & C3 & C4 & $\mathrm{C} 5$ \\
\hline A1 & 32,5 & 16 & 1 & 384 & 1 \\
\hline A2 & 31 & 14 & 1 & 345 & 1 \\
\hline A3 & 25,5 & 16 & 1 & 180 & 1 \\
\hline A4 & 22 & 17,5 & 1 & 124 & 1 \\
\hline A5 & 27,5 & 17,5 & 0,5 & 564 & 1 \\
\hline A6 & 15 & 19,5 & 1 & 371 & 1 \\
\hline A7 & 5 & 5,5 & 1 & 87 & 1 \\
\hline A8 & 15 & 18,5 & 1 & 117 & 1 \\
\hline A9 & 9 & 20,5 & 1 & 261 & 1 \\
\hline A10 & 3 & 18,5 & 0,5 & 49 & 1 \\
\hline A11 & 12 & 19,5 & 0,5 & 137 & 1 \\
\hline A12 & 3 & 17,5 & 1 & 58 & 1 \\
\hline A13 & 3 & 10 & 1 & 20 & 1 \\
\hline A14 & 8 & 14 & 0,5 & 150 & 1 \\
\hline
\end{tabular}

Diketahui Matriks keputusan seperti pada Tabel 2.
Tabel 2. DATA MATRIKS KEPUTUSAN

Berdasarkan Pada Tabel 2 terdapat dua nilai pada baris pertama kolom pertama dan baris kedua kolom pertama dimana peneliti mengambil contoh sampling data pada data matriks keputusan dengan sebagai berikut.

$$
\begin{aligned}
& x 11=32,5 \\
& x 21=31
\end{aligned}
$$

\subsection{Proses Perhitungan SAW}

proses perhitungan SAW merupakan membutuhkan proses normalisasi pada nilai matriks keputusan agar dapat dibandingkan dengan semua rating alternatif yang ada[4].

\section{A. Proses Perhitungan Normalisasi}

Pada proses perhitungan nilai matriks di bagi dengan nilai maksimal di setiap kriteria dengan persamaan (1).

$$
r 11=\frac{\min \{32.5,31,25.5,22,27.5,15,5,15,9,3,12,3,3,8\}}{32.5}=\frac{3}{32.5}=0.0909
$$


$r 11$

$=\frac{\min \{32.5,31,25.5,22,27.5,15,5,15,9,3,12,3,3,8\}}{33}$

$=\frac{3}{33}=0.0968$

Hasil perhitungan normalisasi matriks dapat dilihat pada Tabel 3 .

TABEL 3. HASIL NILAI TER NORMALISASI

\begin{tabular}{|c|c|c|c|c|c|}
\hline \multirow{2}{*}{ Alternatif } & \multicolumn{5}{|c|}{ Kriteria } \\
\hline & $\mathrm{C} 1$ & $\mathrm{C} 2$ & C3 & $\mathrm{C} 4$ & C5 \\
\hline A1 & 0,092 & 0,344 & 0,500 & 0,052 & 1,000 \\
\hline $\mathrm{A} 2$ & 0,097 & 0,393 & 0,500 & 0,058 & 1,000 \\
\hline A3 & 0,118 & 0,344 & 0,500 & 0,111 & 1,000 \\
\hline A4 & 0,136 & 0,314 & 0,500 & 0,161 & 1,000 \\
\hline A5 & 0,109 & 0,314 & 1,000 & 0,035 & 1,000 \\
\hline A6 & 0,200 & 0,282 & 0,500 & 0,054 & 1,000 \\
\hline A7 & 0,600 & 1,000 & 0,500 & 0,230 & 1,000 \\
\hline A8 & 0,200 & 0,297 & 0,500 & 0,171 & 1,000 \\
\hline A9 & 0,333 & 0,268 & 0,500 & 0,077 & 1,000 \\
\hline A10 & 1,000 & 0,297 & 1,000 & 0,408 & 1,000 \\
\hline A11 & 0,250 & 0,282 & 1,000 & 0,146 & 1,000 \\
\hline A12 & 1,000 & 0,314 & 0,500 & 0,345 & 1,000 \\
\hline A13 & 1,000 & 0,550 & 0,500 & 1,000 & 1,000 \\
\hline A14 & 0,375 & 0,393 & 1,000 & 0,133 & 1,000 \\
\hline
\end{tabular}

\section{B. Proses Perhitungan Pembobot}

Pada proses perhitungan pembobot di kali dengan rating kinerja yang sudah ternormalisasi dengan persamaan (2).

$$
\begin{gathered}
V_{1}=0,2 * 0,092=0.0184 \\
V_{2}=0,2 * 0,97=0,194
\end{gathered}
$$

Hasil perhitungan pembobot dapat di lihat pada tabel 4.

\begin{tabular}{|c|c|c|c|c|c|}
\hline \multirow{2}{*}{$\begin{array}{c}\text { Alternati } \\
\mathrm{f}\end{array}$} & \multicolumn{5}{|c|}{ Kriteria } \\
\hline & $\mathrm{C} 1$ & $\mathrm{C} 2$ & $\mathrm{C} 3$ & $\mathrm{C} 4$ & $\mathrm{C} 5$ \\
\hline \multirow{3}{*}{ A1 } & 0,018 & 0,068 & 0,100 & 0,010 & \\
\hline & 5 & 8 & 0 & 4 & 0,2000 \\
\hline & 0,019 & 0,078 & 0,100 & 0,011 & \\
\hline \multirow[t]{2}{*}{ A2 } & 4 & 6 & 0 & 6 & 0,2000 \\
\hline & 0,023 & 0,068 & 0,100 & 0,022 & \\
\hline \multirow[t]{2}{*}{ A3 } & 5 & 8 & 0 & 2 & 0,2000 \\
\hline & 0,027 & 0,062 & 0,100 & 0,032 & \\
\hline \multirow[t]{2}{*}{ A4 } & 3 & 9 & 0 & 3 & 0,2000 \\
\hline & 0,021 & 0,062 & 0,200 & 0,007 & \\
\hline \multirow[t]{2}{*}{ A5 } & 8 & 9 & 0 & 1 & 0,2000 \\
\hline & 0,040 & 0,056 & 0,100 & 0,010 & \\
\hline \multirow[t]{2}{*}{ A6 } & 0 & 4 & 0 & 8 & 0,2000 \\
\hline & 0,120 & 0,200 & 0,100 & 0,046 & \\
\hline \multirow[t]{2}{*}{ A7 } & 0 & 0 & 0 & 0 & 0,2000 \\
\hline & 0,040 & 0,059 & 0,100 & 0,034 & \\
\hline \multirow[t]{2}{*}{ A8 } & 0 & 5 & 0 & 2 & 0,2000 \\
\hline & 0,066 & 0,053 & 0,100 & 0,015 & \\
\hline \multirow[t]{2}{*}{ A9 } & 7 & 7 & 0 & 3 & 0,2000 \\
\hline & 0,200 & 0,059 & 0,200 & 0,081 & \\
\hline \multirow[t]{2}{*}{ A10 } & 0 & 5 & 0 & 6 & 0,2000 \\
\hline & 0,050 & 0,056 & 0,200 & 0,029 & \\
\hline \multirow[t]{2}{*}{ A11 } & 0 & 4 & 0 & 2 & 0,2000 \\
\hline & 0,200 & 0,062 & 0,100 & 0,069 & \\
\hline \multirow[t]{2}{*}{ A12 } & 0 & 9 & 0 & 0 & 0,2000 \\
\hline & 0,200 & 0,110 & 0,100 & 0,200 & \\
\hline \multirow[t]{2}{*}{ A13 } & 0 & 0 & 0 & 0 & 0,2000 \\
\hline & 0,075 & 0,078 & 0,200 & 0,026 & \\
\hline A 14 & 0 & 6 & 0 & 7 & 0,2000 \\
\hline
\end{tabular}

TABEL 4. HASIL PERHITUNGAN PEMBOBOT

\section{Proses Penjumlahan dan perankingan}

Pada proses penjumlahan dan perankingan semua kriteria dari hasil perhitungan pembobot berdasarkan alternatif di jumlahkan dengan persamaan (3).

$$
\begin{gathered}
U_{1}=0,0185+0,0688+, 0,1+0,0104+0,2 \\
=0,3976
\end{gathered}
$$


Nurhadinata, dkk., Implementasi Metode Simple Additive Weighting (SAW) Pada Penilaian Kinerja Standar Pelayanan Minimal Sarana dan Prasarana Pendidikan Dasar Pada Kota Samarinda

$$
\begin{gathered}
U_{2}=0,0194+0,0786+0,1+0,0116+0,2 \\
=0,4095
\end{gathered}
$$

Hasil penjumlahan dan ranking pada setiap alternatif dapat di lihat pada Tabel 5.

TABEL 5. HASIL PENJUMLAHAN SEMUA KRITERIA

\begin{tabular}{c|c|c}
\hline Alternatif & Jumlah & ranking \\
\hline A1 & 0,3976 & 14 \\
\hline A2 & 0,4095 & 12 \\
\hline A3 & 0,4145 & 11 \\
\hline A4 & 0,4224 & 10 \\
\hline A5 & 0,4918 & 7 \\
\hline A6 & 0,4072 & 13 \\
\hline A7 & 0,6660 & 3 \\
\hline A8 & 0,4336 & 9 \\
\hline A9 & 0,4357 & 8 \\
\hline A10 & 0,7411 & 2 \\
\hline A11 & 0,5356 & 6 \\
\hline A12 & 0,6318 & 4 \\
\hline A13 & 0,8100 & 1 \\
\hline A14 & 0,5802 & 5 \\
\hline & &
\end{tabular}

\subsection{Penerapan Aplikasi}

Perhitungan SAW menggunakan aplikasi merupakan bentuk implementasi metode SAW. Agar dapat membandingkan Perhitungan manual dengan perhitungan pada aplikasi.

\section{A. Normalisasi}

Di salah satu perhitungan metode SAW. perlu di lakukan proses normalisasi agar dapat diperbandingkan dengan semua alternatif yang ada. Maka hasil dari normalisasi pada aplikasi ini terdapat informasi seperti kode sekolah, nama sekolah, dan kriteria dengan kode dari C1 sampai dengan C5.
Normalisasi

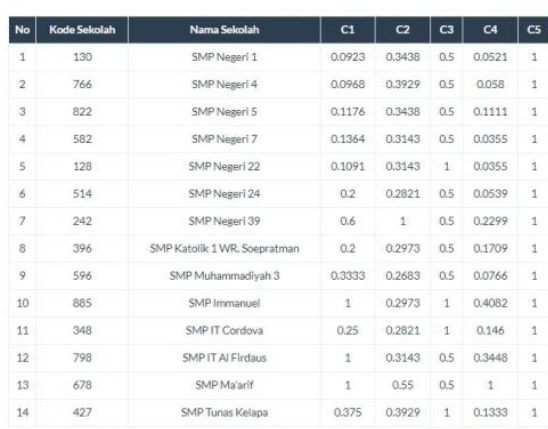

Gambar. 3. Hasil Normalisasi

\section{B. Perankingan}

Untuk bisa mencari penjumlahan terbobot dari rating kinerja. Perlu adanya perankingan pada setiap alternatif. Pada tampilan aplikasi ini, terdapat juga informasi tambahan seperti nilai dan ranking pada setiap alternatif.

\begin{tabular}{|c|c|c|c|c|}
\hline No & Kode Sekolah & Nama scholah & Nilai & Ranking \\
\hline 1 & 130 & SMP Neger 1 & 0.3977 & 13 \\
\hline 2 & 766 & SMP Negeri 4 & 0.4096 & 11 \\
\hline 3 & 822 & SMP Negeri 5 & 0.4145 & 10 \\
\hline 4 & 582 & SMP Negeri7 & 0.3973 & 14 \\
\hline 5 & 128 & SMP Negeriz2 & 0.4918 & 7 \\
\hline 6 & 514 & SMP Negeri24 & 0.4072 & 12 \\
\hline 7 & 242 & SMP Negeri39 & 0.666 & 3 \\
\hline 8 & 396 & SMP Ketolik 1 WR. Soepratman & 0.4337 & 9 \\
\hline 9 & 596 & SMP Muharmadiyah 3 & 0.4357 & ${ }^{\circ}$ \\
\hline 10 & 885 & SMP Immanuel & 0.7411 & 2 \\
\hline 11 & 348 & SMP IT Cordova & 0.5356 & 6 \\
\hline 12 & 790 & SMPIT A Firdaus & 0.6319 & 4 \\
\hline 13 & 678 & SMP Ma'arif & 0.81 & 1 \\
\hline 14 & 427 & SMP Tunas Kelapa & 0.5803 & 5 \\
\hline
\end{tabular}

Penilaian Kinerja

Gambar. 4. Hasil Nilai Perankingan

\section{KESIMPULAN}

Dari hasil penelitian diatas dapat disimpulkan bahwa penerapan metode Simple Additive Weighting (SAW) untuk menentukan calon sekolah terbaik berdasarkan penilaian kinerja standar pelayanan minimal pendidikan dasar pada kota samarinda. Informasi yang ditampilkan adalah setiap alternatif, mulai dari nilai terbesar ke terkecil. Nilai terbesar yaitu nilai yang mendekati angka 1 (satu). Metode Simple additive weighting (SAW) digunakan untuk menerapkan kriteria Rombongan belajar tidak melebihi 36 murid dan tersedia 1 ruang kelas, Setiap sekolah terdapat ruang lab IPA yang cukup 36 peserta, Setiap sekolah terdapat 1 ruang guru yang dilengkapi meja dan kursi, Setiap sekolah tersedia buku, Setiap sekolah memiliki buku pengayaan dan buku referensi. Berdasarkan hasil perbandingan antara perhitungan manual menggunakan metode 
Simple additive weighting (SAW) dengan data di apikasi diperoleh hasil yang sesuai sebanyak 95\% dari 14 data alternatif dan sekolah yang berada di peringkat 1 ialah SMP Ma'arif, peringkat 2 ialah SMP Immanuel, dan peringkat 3 ialah SMP Negeri 39.

\section{REFERENSI}

[1] (2013). PERATURAN MENTERI PENDIDIKAN DAN KEBUDAYAAN REPUBLIK INDONESIA NOMOR 23 TAHUN 2013. jakarta.

[2] Ekasari Nugraheni, H. K. (t.thn.). Perancangan Sistem Pendukung Keputusan untuk Memantau. 1-6.

[3] Eniyati, S. (2011). Perancangan Sistem Pendukung Pengambilan Keputusan untuk Penerimaan beasiswa dengan metode SAW. Jurnal Teknologi Informasi DINAMIK Volume 16, No.2, hal 171-176.

[4] Kusumadewi, S. H. (2006). FUZZY MULTIATTRIBUTE DECISION MAKING (FUZZY $M A D M)$. Yogyakarta: GRAHA ILMU.

[5] Made Astradanta, I. M. (2016). Pengembangan Sistem Penunjang Keputusan Pemilihan Tempat Kuliner Dengan Menggunakan Metode AHP Dan SAW. Jurusan Pendidikan Teknik Informatika Universitas Pendidikan Ganesha Singaraja, Bali, 1 - 11.

[6] Oktaputra, A. W. (2014). Sistem Pendukung Keputusan Kelayakan Pemberian Kredit Motor Menggunakan Metode Simple Additive Weighting Pada Perusahaan Leasing HD Finance 